\title{
As principais causas que levam a automutilação em adolescentes: uma revisão integrativa
}

\author{
The main causes that lead to self-harm in adolescents: an integrative review \\ Las principales causas que conducen a la autolesión en adolescentes: una revisión \\ integradora
}

Andressa de Oliveira $^{1 \star}$, Sabrinna Barbosa de Souza ${ }^{1}$, Nelzir Martins Costa ${ }^{1}$.

\begin{abstract}
RESUMO
Objetivo: Identificar os fatores causais em adolescentes que estimulam o aumento de casos de autolesão. Métodos: Tratou-se de uma revisão integrativa de literatura, de caráter qualitativa e descritiva. Foram selecionadas 40 bibliografias das plataformas Scientific Electronic Library Online (Scielo), PUBMED, Acervo+, Periódicos Eletrônicos em Psicologia (PePSIC) e Semantic Scholar dos últimos 6 anos, sendo apenas 15 literaturas aptas para a revisão a partir dos critérios de inclusão e exclusão. Resultados: Os principais fatores envolveram aspectos pessoais, familiares, transtornos psiquiátricos, relacionados à infância e risco sociais. Além do mais, identificou que os transtornos psiquiátricos e o uso inadequado da internet influenciam negativamente no comportamento autolesivo. Adolescentes que se automutilam não possuem a intenção consciente de cometer suicídio, mas sim uma forma de diminuir o seu sofrimento, apesar do ato ser um fator de risco para que isso ocorra. Considerações finais: Buscou-se conhecer as causas que justificam a automutilação entre esses jovens, que permite identificar de forma precoce e prevenir a ocorrência de novos casos. Além disso, é importante a quebra do tabu sobre automutilação entre jovens, informando profissionais da educação para combater a negligência em relação a este tema.
\end{abstract}

Palavras-chave: Adolescentes, Angústia emocional, Automutilação, Transtornos mentais.

\begin{abstract}
Objective: To identify causal factors in adolescents that encourage an increase in cases of self-injury. Methods: This was an integrative literature review, qualitative and descriptive. 40 bibliographies from the Scientific Electronic Library Online (Scielo), PUBMED, Acervo+, Electronic Journals in Psychology (PePSIC) and Semantic Scholar platforms from the last 6 years were selected, with only 15 literatures suitable for review based on the inclusion and exclusion criteria. Results: The main factors involved personal and family aspects, psychiatric disorders, childhood-related and social risks. Furthermore, it identified that psychiatric disorders and inappropriate internet use negatively influence self-injurious behavior. Adolescents who self-mutilate do not have the conscious intention of committing suicide, but rather a way to reduce their suffering, despite the act being a risk factor for this to occur. Final considerations: We sought to know the causes that justify selfmutilation among these young people, which allows for early identification and prevention of the occurrence of new cases. In addition, it is important to break the taboo on self-mutilation among young people, informing education professionals to fight neglect in relation to this topic.
\end{abstract}

Keywords: Adolescents, Emotional distress, Self-mutilation, Mental disorders.

\section{RESUMEN}

Objetivo: Identificar factores causales en adolescentes que favorezcan el aumento de casos de autolesiones. Métodos: Se realizó una revisión bibliográfica integradora, cualitativa y descriptiva. Se seleccionaron 40 bibliografías de las plataformas Scientific Electronic Library Online (Scielo), PUBMED, Acervo +, Revistas electrónicas de psicología (PePSIC) y Semantic Scholar de los últimos 6 años, con solo 15 literaturas aptas para revisión en base a los criterios de inclusión y exclusión. Resultados: Los principales factores involucraron aspectos personales y familiares, trastornos psiquiátricos, riesgos sociales y relacionados con la infancia. Además, identificó que los trastornos psiquiátricos y el uso inadecuado de Internet influyen

1 Instituto Tocantinense Presidente Antônio Carlos (ITPAC), Porto Nacional - TO.

*E-mail: andressa2629@gmail.com

SUBMETIDO EM: 6/2021

ACEITO EM: 6/2021

PUBLICADO EM: 6/2021 
negativamente en el comportamiento autolesivo. Los adolescentes que se automutilan no tienen la intención consciente de suicidarse, sino una forma de reducir su sufrimiento, a pesar de que el acto sea un factor de riesgo para que esto ocurra. Consideraciones finales: Se buscó conocer las causas que justifican la automutilación entre estos jóvenes, lo que permite la identificación temprana y prevención de la ocurrencia de nuevos casos. Además, es importante romper el tabú de la automutilación entre los jóvenes, informando a los profesionales de la educación para que luchen contra el abandono en relación con este tema.

Palabras clave: Adolescentes, Angustia emocional, Automutilación, Trastornos mentales.

\section{INTRODUÇÃO}

A adolescência é marcada por mudanças físicas e psicossociais, na qual o indivíduo deve lidar com a sua imagem corporal e como utilizá-la por meio de um instrumento relacional com o mundo. Dessa maneira, surgem desafios que exigem uma maturidade emocional para assumir uma identidade de um indivíduo adulto. Diante disso, o adolescente enfrenta frustações, angústias e se encontra incapaz de expressá-los verbalmente procurando outros meios para se "libertar", como a autolesão, porém o fator causador não está sendo solucionado, fazendo com que essa ação seja recorrente (RODRIGUES PP, 2018; CIDADE NOP e ZORNIG SMAJ, 2021).

A pele tem como função proteger, principalmente, os órgãos vitais, além de fazer parte da identificação de cada indivíduo. Com isso, para esses adolescentes a pele foi considerada uma grande barreira que aprisiona, mesmo que simbolicamente, esse sentimento ou sensação ruim. A angústia desencadeada pela incapacidade de lidar com o fator causador, acaba por levar o adolescente a se comunicar marcando sua pele, sendo uma forma de exteriorizar aquilo que não consegue ser dito em palavras (OLIVEIRA TA, 2016).

Vários são os fatores de riscos que predispõem essa automutilação, sendo uma lesão que o indivíduo inflige em si próprio, dentre eles o abuso emocional, físico, social, maus tratos infantis, problemas familiares, o fato de conhecer algum membro familiar ou amigo que praticou essa automutilação, a presença de transtornos psíquicos, ou sintomas depressivos e ansiosos, vítimas de bullying, baixa autoestima ou até mesmo abuso de álcool entre outras drogas (FREITAS EQ e SOUZA R, 2017).

No Brasil, a notificação de violências interpessoais e autoprovocadas integra a lista de doenças e agravos de notificação compulsória no Sistema de Notificação de Agravos de Notificação (SINAN) em serviços sentinelas, ampliando para notificação universal em 2011 (BRASIL, 2020b). Apesar da gravidade e de constituir-se como um problema de saúde pública, não há muitos estudos voltados para a análise do tema.

Segundo o Boletim Epidemiológico da Secretaria de Vigilância em Saúde do Ministério da Saúde (2019), no período de 2011 a 2018 foram notificados 339.730 casos de automutilação. Desse total, 154.279 (45,4\%) ocorreram na faixa etária de 15 a 29 anos. No Estado do Tocantins foram registradas, no mesmo período, um total de 2.566 notificações. Ao final de 2018 esses dados devem ter aumentado, visto que o levantamento foi realizado com dados coletados até 2 de agosto de 2018.

Em virtude desses dados, percebeu-se que a automutilação é um problema de saúde pública, exigindo estudos que busquem aprofundar o conhecimento sobre o tema, para que os profissionais de saúde sejam capacitados para lidarem com estes casos, bem como os prevenir. O presente artigo objetivou apresentar uma análise sobre a automutilação em jovens e adolescentes no Brasil, analisando as causas que contribuem para o aumento dos casos e o perfil dos autores, a partir de revisão da literatura.

\section{MÉTODOS}

Tratou-se de uma revisão de literatura do tipo integrativa, de caráter qualitativa e descritiva, com a finalidade de investigar as causas do número crescente de casos de automutilação em adolescentes, a partir de pesquisas já realizadas. O estudo consistiu na realização de busca de artigos científicos dos últimos 6 anos (2016 a 2021) publicados em revistas, jornais e livros, encontradas nas plataformas Scientific Electronic Library Online (Scielo), PUBMED, Acervo+, Periódicos Eletrônicos em Psicologia (PePSIC) e Semantic Scholar. Os Descritores em Ciências da Saúde utilizados foram: adolescentes, angústia emocional, automutilação e transtornos mentais. 
Os artigos foram selecionados a partir da elaboração da pergunta norteadora "Por quais motivos há um crescente número de casos de automutilação entre adolescentes?". O levantamento bibliográfico foi realizado a partir dos critérios de inclusão, sendo aqueles que respondem à pergunta norteadora, amostragem, objetivo de estudo, tipo de estudo e, sendo analisados na língua portuguesa e inglesa e critérios de exclusão como ano de publicação e local de publicação.

Foi realizado uma busca diversificada de artigos de acordo com os critérios de inclusão e exclusão, com leitura de resumos e títulos, e posteriormente leitura completa; extração de dados com análise crítica de cada estudo e das características; comparação dos resultados, e por fim, apresentação da revisão em si.

\section{RESULTADOS}

Dentre as 15 publicações selecionadas, 33,33\% (5 artigos) são da plataforma Acervo +, todos escritos na língua portuguesa, sendo 20\% desses artigos (1 artigo) do ano de 2019, 40\% (2 artigos) do ano de 2020 e $40 \%$ (2 artigos) são de $2021 ; 13,33 \%$ (2 artigos) tiveram como base de dados a plataforma PePSIC, sendo $50 \%$ (1 artigo) do ano de 2017 e 50\% (1 do ano) de 2019; 26,66\% (4 artigos) foram encontrados na plataforma PUBMED, todos escritos em língua inglesa, sendo que $25 \%$ desses artigos ( 1 artigo) é do ano de 2019 e $75 \%$ (3 artigos) são do ano de 2020; 13,33\% (2 artigos) são da base de dados SciELO, todos escritos na língua portuguesa, em que 50\% (1 artigo) é do ano de 2016 escrito em língua inglesa e 50\% (1 artigo) do ano de 2020 escrito em língua portuguesa; e 13,33\% (2 artigos) da plataforma Semantic Scholar, todos escritos em língua portuguesa, em que 50\% (1 artigo) é do ano de 2018 e 50\% (1 artigo) do ano de 2019 (Figura 1).

Figura 1 - Fluxograma dos critérios estabelecidos para a seleção e exclusão dos estudos nos anos 2016 a 2021.

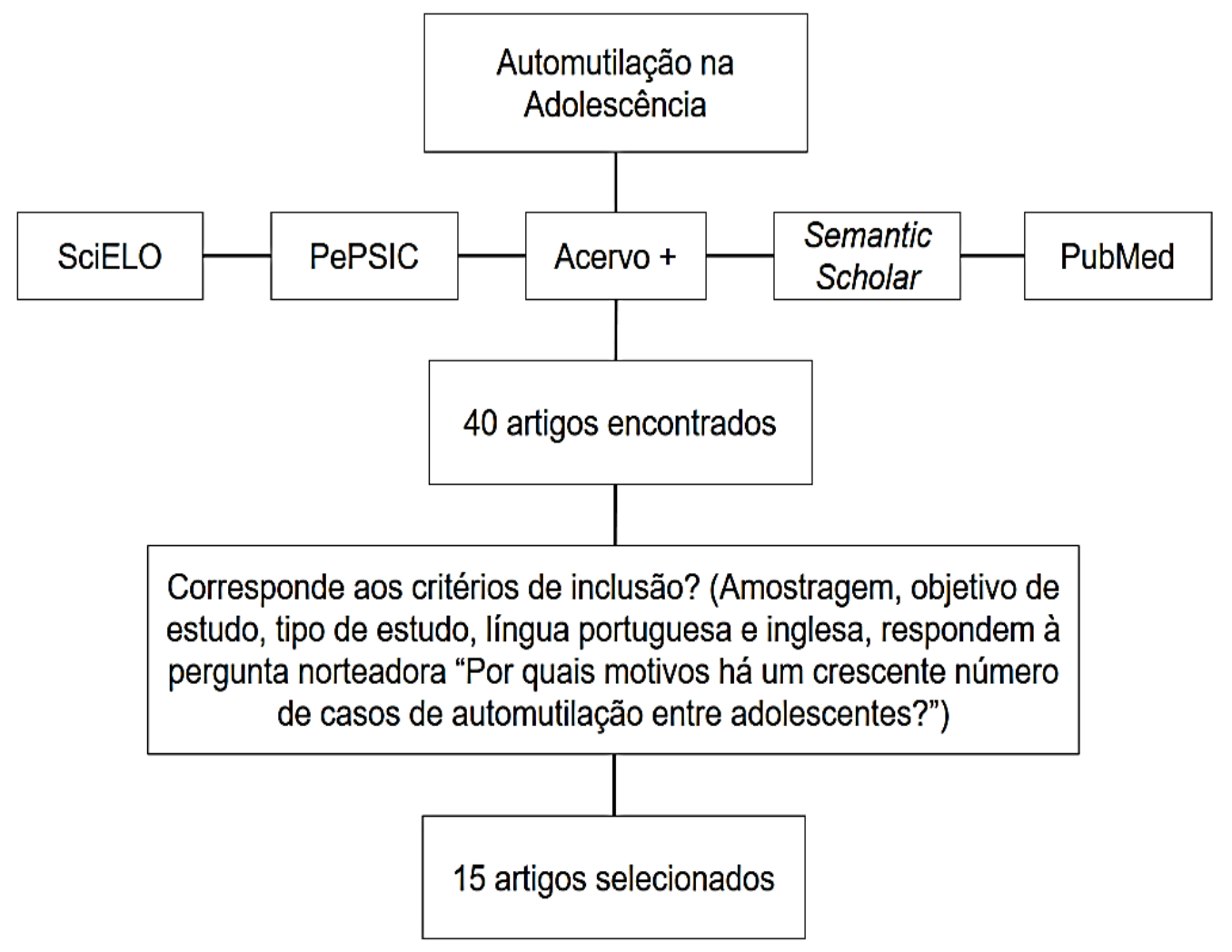

Fonte: Oliveira A, et al., 2021.

Durante a busca, foram definidas 15 publicações para serem utilizadas neste estudo. Foram encontrados 40 artigos, contudo 25 foram eliminados por não se enquadrarem nos critérios avaliados para a pesquisa. Em relação ao planejamento metodológico dos estudos utilizados, a maioria foram de caráter qualitativo que equivale a 11 artigos e 4 artigos quantitativos (Quadro 1). 
Quadro 1- Publicações selecionadas para análise dos dados segundo autor, título, ano de publicação, periódico e objetivos.

\begin{tabular}{|c|c|c|c|c|}
\hline Autores/Ano & Título & Periódico & Objetivos & $\begin{array}{l}\text { Principais Resultados } \\
\end{array}$ \\
\hline $\begin{array}{c}\text { FREITAS EQ e SOUZA } \\
\text { R (2017). }\end{array}$ & $\begin{array}{l}\text { Automutilação } \\
\text { adolescência: prevenção e e } \\
\text { intervenção em psicologia } \\
\text { escolar. }\end{array}$ & Revista Ciência. & $\begin{array}{l}\text { Apresentar a contribuição da } \\
\text { Psicologia Escolar na redução dos } \\
\text { casos de automutilação. }\end{array}$ & $\begin{array}{l}\text { O Psicólogo Escolar ao trabalhar a automutilação, } \\
\text { em caráter preventivo, utiliza de ações que } \\
\text { contribuem para a redução de casos no ambiente } \\
\text { escolar, apresentam um papel importante para a } \\
\text { sinalização, diagnóstico, acompanhamento e } \\
\text { encaminhamento para os devidos profissionais. }\end{array}$ \\
\hline $\begin{array}{l}\text { IZADI-MAZIDI M, et al. } \\
\text { (2019). }\end{array}$ & $\begin{array}{l}\text { Avaliação das funções da } \\
\text { autolesão não suicida: análise } \\
\text { fatorial da avaliação funcional } \\
\text { da automutilação entre } \\
\text { adolescentes. }\end{array}$ & $\begin{array}{l}\text { Iranian journal } \\
\text { psychiatry. }\end{array}$ & $\begin{array}{lcr}\text { Avaliar a } & \text { análise fatorial } & \text { da } \\
\text { Avaliação } & \text { Funcional } & \text { da } \\
\text { Automutilação } & \text { (FASM) } & \text { entre } \\
\text { adolescentes } & \text { iranianos } & \text { com } \\
\text { autolesão não suicida. } & \end{array}$ & $\begin{array}{l}\text { Os resultados da análise fatorial confirmatória } \\
\text { apoiaram o modelo de } 4 \text { fatores das funções NSSI } \\
\text { sugerido por Nock e Prinstine }[X 2 / \mathrm{df}=1,84 ; \\
\mathrm{RMSEA}=0,07 ; \mathrm{GFI}=0,82 ; \mathrm{AGFI}=0,77] \text {. A função } \\
\text { mais frequente para se engajar no NSSI foi o } \\
\text { Reforço Negativo Automático. }\end{array}$ \\
\hline LIMA CSA, et al. (2021). & $\begin{array}{l}\text { Transtorno de Personalidade } \\
\text { Borderline e sua relação com } \\
\text { os comportamentos } \\
\text { autodestrutivos e suicídio. }\end{array}$ & $\begin{array}{l}\text { Revista Eletrônica Acervo } \\
\text { Saúde. }\end{array}$ & $\begin{array}{l}\text { Identificar e revisar como os } \\
\text { impactos negativos do Transtorno } \\
\text { de Borderline influenciam no dia do } \\
\text { paciente e suas consequências } \\
\text { mais variadas que tal transtorno traz } \\
\text { hodiernamente ao indivíduo. }\end{array}$ & $\begin{array}{l}\text { Este estudo reforçou a associação entre o } \\
\text { Transtorno de Personalidade Borderline, } \\
\text { comportamentos autodestrutivos e suicídio, } \\
\text { evidenciando a urgência em amenizar o sofrimento } \\
\text { emocional e os comportamentos prejudiciais dos } \\
\text { acometidos por este Transtorno. }\end{array}$ \\
\hline LIMA SO, et al. (2020). & $\begin{array}{l}\text { Impactos no comportamento e } \\
\text { na saúde mental de grupos } \\
\text { vulneráveis em época de } \\
\text { enfrentamento da infecção } \\
\text { COVID-19: revisão narrativa. }\end{array}$ & $\begin{array}{l}\text { Revista Eletrônica Acervo } \\
\text { Saúde. }\end{array}$ & $\begin{array}{l}\text { Realizar uma revisão narrativa das } \\
\text { repercussões no comportamento e } \\
\text { na saúde mental da população } \\
\text { vulnerável e de medidas adotadas, } \\
\text { no enfrentamento da pandemia do } \\
\text { COVID-19. }\end{array}$ & $\begin{array}{l}\text { As repercussões da pandemia do COVID-19 são } \\
\text { comparadas a desastres naturais e guerras, pelo } \\
\text { receio em adoecer, ficar desempregado, } \\
\text { desamparado, ser estigmatizado caso venha a se } \\
\text { infectar e, o medo de morrer. A sensação de } \\
\text { incerteza quanto ao futuro econômico e } \\
\text { educacional traz também implicações na saúde } \\
\text { mental. Estratégias sociais, educacionais, } \\
\text { econômicas devem ser implantadas para } \\
\text { minimizar os danos causados pela COVID-19. }\end{array}$ \\
\hline LI W, et al. (2020). & $\begin{array}{l}\text { Progressão dos serviços de } \\
\text { saúde mental durante o surto } \\
\text { de COVID-19 na China. }\end{array}$ & $\begin{array}{l}\text { International journal } \\
\text { biological sciences. }\end{array}$ & $\begin{array}{l}\text { Analisar os serviços de saúde } \\
\text { mental durante o surto de COVID- } \\
19 \text { na China. }\end{array}$ & $\begin{array}{l}\text { O surto do COVID-19 causou enormes problemas } \\
\text { psicológicos em diferentes subpopulações. Apesar } \\
\text { de as autoridades chinesas terem anunciado } \\
\text { políticas relevantes e princípios atuantes de } \\
\text { maneira estratégica, o surto de COVID-19 } \\
\text { representou um sério desafio emergente para os } \\
\text { serviços de saúde mental na China. }\end{array}$ \\
\hline
\end{tabular}




\begin{tabular}{|c|c|c|c|c|}
\hline Autores/ Ano & Título & Periódico & Objetivos & $\begin{array}{l}\text { Principais Resultados } \\
\end{array}$ \\
\hline $\begin{array}{l}\text { LOPES LS E TEIXEIRA } \\
\text { LC (2019). }\end{array}$ & $\begin{array}{l}\text { Automutilações na } \\
\text { adolescência e suas narrativas } \\
\text { em contexto escolar. }\end{array}$ & $\begin{array}{l}\text { Estilos da Clínica - } \\
\text { Revista USP. }\end{array}$ & $\begin{array}{l}\text { Discutir a automutilação e suas } \\
\text { narrativas por adolescentes em } \\
\text { contexto escolar. }\end{array}$ & $\begin{array}{l}\text { A partir de estudos de casos de uma escola } \\
\text { privada em Fortaleza, são discutidos os seguintes } \\
\text { aspectos: autolesão e os efeitos na escola, } \\
\text { conflitos sociofamiliares e processo de } \\
\text { subjetivação adolescente. Conclui-se que a partir } \\
\text { de uma escuta qualificada na escola é possível dar } \\
\text { voz aos adolescentes para que possam produzir } \\
\text { um saber sobre si, e ao seu modo sustentar seu } \\
\text { mal-estar. }\end{array}$ \\
\hline $\begin{array}{l}\text { MORAES DX, et al. } \\
\text { (2020). }\end{array}$ & $\begin{array}{l}\text { "Caneta é a lâmina, minha pele } \\
\text { o papel": fatores de risco da } \\
\text { automutilação } \\
\text { adolescentes. }\end{array}$ & $\begin{array}{l}\text { Revista Brasileira de } \\
\text { Enfermagem. }\end{array}$ & $\begin{array}{l}\text { Descrever os fatores de risco que } \\
\text { influenciam o comportamento da } \\
\text { automutilação de adolescentes em } \\
\text { atendimento em um Centro de } \\
\text { Atenção Psicossocial Infantojuvenil, } \\
\text { na percepção do próprio sujeito. }\end{array}$ & $\begin{array}{l}\text { Na categoria Fatores de risco, surgiram quatro } \\
\text { subcategorias: Fatores de adversidade familiar; } \\
\text { Contágio social; Acontecimentos adversos de vida; } \\
\text { Características pessoais. Conflitos, falta de } \\
\text { suporte, uso de drogas na família, conhecer } \\
\text { alguém que se corta, redes sociais, religiosidade, } \\
\text { histórico de violência sexual e bullying foram } \\
\text { identificados como fatores de risco que influenciam } \\
\text { na automutilação. }\end{array}$ \\
\hline $\begin{array}{l}\text { MOREIRA ES, et al. } \\
\text { (2020). }\end{array}$ & $\begin{array}{l}\text { Auto-mutilação } r \text { em } \\
\text { adolescentes: uma revisão } \\
\text { integrativa da literatura. }\end{array}$ & Ciência \& Saúde Coletiva. & $\begin{array}{l}\text { Apresentar uma síntese das } \\
\text { produções científicas a respeito da } \\
\text { automutilação em adolescentes no } \\
\text { período de janeiro de } 2012 \text { a junho } \\
\text { de } 2017 \text {. }\end{array}$ & $\begin{array}{l}\text { Muitos são os estudos com finalidade de } \\
\text { compreender as funções da automutilação e de } \\
\text { validação de instrumentos que avaliem o } \\
\text { comportamento, entretanto, } \\
\text { insuficiência de estudos que avaliem a trajetória da } \\
\text { automutilação ao longo da vida. }\end{array}$ \\
\hline $\begin{array}{l}\text { PEREIRA RG, et al. } \\
\text { (2019). }\end{array}$ & $\begin{array}{l}\text { Análise do perfil do paciente } \\
\text { suicida: revisão integrativa. }\end{array}$ & $\begin{array}{l}\text { Revista Eletrônica Acervo } \\
\text { Saúde. }\end{array}$ & $\begin{array}{l}\text { Identificar por meio da literatura qual } \\
\text { o perfil do paciente suicida. }\end{array}$ & $\begin{array}{l}\text { A maioria das vítimas de tentativa de suicídio são } \\
\text { jovens do gênero masculino. Quanto ao perfil } \\
\text { emocional da pessoa suicida segundo os estudos, } \\
\text { foi relacionado um perfil de pessoas com } \\
\text { depressão, ansiedade, melancolismo, com baixo } \\
\text { autoestima, sentindo-se desamparados, e com } \\
\text { desesperança em relação a vida. }\end{array}$ \\
\hline REIS CES (2018). & $\begin{array}{l}\text { Do corpo objeto ao corpo } \\
\text { vivido: aproximações } \\
\text { automutilação } \\
\text { fenomenologia. }\end{array}$ & Revista IGT na Rede. & $\begin{array}{l}\text { Realizar paralelos com a concepção } \\
\text { fenomenológica de corpo de } \\
\text { Merleau-Ponty } \\
\text { automutilação. com }\end{array}$ & $\begin{array}{l}\text { Destaca-se aqui, o distanciamento que ocorreu } \\
\text { entre o homem e seu corpo durante os tempos. Em } \\
\text { contrapartida, Merleau-Ponty (1999) enaltece a } \\
\text { busca pela reaproximação com o corpo fenomenal } \\
\text { cuja distância continua a existir na } \\
\text { contemporaneidade. }\end{array}$ \\
\hline
\end{tabular}




\begin{tabular}{|c|c|c|c|c|}
\hline Autores/ Ano & Título & Periódico & Objetivos & Principais Resultados \\
\hline $\begin{array}{l}\text { SANTOS NM, et al. } \\
(2021) .\end{array}$ & $\begin{array}{l}\text { Prevalência de ideação suicida } \\
\text { em acadêmicos da área de } \\
\text { saúde. }\end{array}$ & $\begin{array}{l}\text { Revista Eletrônica Acervo } \\
\text { Saúde. }\end{array}$ & $\begin{array}{l}\text { Estimar a prevalência de ideação } \\
\text { suicida em acadêmicos da área de } \\
\text { saúde. }\end{array}$ & $\begin{array}{l}\text { Dos } 80 \text { acadêmicos que apresentaram ideação } \\
\text { suicida, a prevalência foi de } 36 \% \text {, verificou-se que } \\
\text { a média de idade foi de } 20 \text { anos. Os fatores } \\
\text { associados a ideação suicida foram: sexo, } \\
\text { depressão moderada a grave e histórico de } \\
\text { comportamento suicida. }\end{array}$ \\
\hline $\begin{array}{l}\text { TANG J, et al. } \\
\text { (2020). }\end{array}$ & $\begin{array}{l}\text { Associação de dependência de } \\
\text { internet com autolesão não } \\
\text { suicida entre adolescentes na } \\
\text { China. }\end{array}$ & JAMA network open. & $\begin{array}{l}\text { Examinar a ocorrência de } \\
\text { dependência de internet com } \\
\text { autolesão não suicida e quaisquer } \\
\text { diferenças de sexo entre } \\
\text { adolescentes chineses. }\end{array}$ & $\begin{array}{l}\text { Neste estudo de pesquisa com } 15.623 \\
\text { adolescentes na China, tanto o possível vício em } \\
\text { Internet quanto o vício em Internet foram } \\
\text { associados à automutilação não suicida. Não } \\
\text { houve diferenças nas associações por sexo ou } \\
\text { idade. }\end{array}$ \\
\hline $\begin{array}{l}\text { TENÓRIO MMC, et al. } \\
\text { (2019). }\end{array}$ & $\begin{array}{l}\text { A percepção de psicólogos } \\
\text { acerca da automutilação em } \\
\text { jovens. }\end{array}$ & Revista Cientifico. & $\begin{array}{l}\text { Analisar a percepção de } \\
\text { profissionais da psicologia sobre os } \\
\text { fatores que incitam a automutilação } \\
\text { em jovens, investigando as } \\
\text { influências de fatores psicossociais } \\
\text { e midiáticos em tais práticas. }\end{array}$ & $\begin{array}{l}\text { Os resultados obtidos apontam para uma } \\
\text { prevalência do comportamento autolesivo em } \\
\text { jovens com idades entre } 11 \text { e } 20 \text { anos, } \\
\text { notadamente no gênero feminino. Observou-se } \\
\text { que o comportamento autolesivo ocorre com maior } \\
\text { frequência em jovens que enfrentam dificuldades } \\
\text { relacionais, emocionais, comunicacionais e } \\
\text { problemas socioeconômicos. }\end{array}$ \\
\hline $\begin{array}{l}\text { VASCONCELOS SE, et } \\
\text { al. (2020). }\end{array}$ & $\begin{array}{l}\text { Impactos de uma pandemia na } \\
\text { saúde mental: analisando o } \\
\text { efeito causado pelo COVID-19. }\end{array}$ & $\begin{array}{l}\text { Revista Eletrônica Acervo } \\
\text { Saúde. }\end{array}$ & $\begin{array}{l}\text { Investigar as implicações na saúde } \\
\text { mental em decorrência de surtos e } \\
\text { de pandemias, com enfoque na } \\
\text { COVID-19. }\end{array}$ & $\begin{array}{l}\text { A literatura é clara no que se refere aos impactos } \\
\text { na saúde mental de toda a população durante uma } \\
\text { pandemia, sendo capaz de repercutir na qualidade } \\
\text { de vida tanto individualmente quanto } \\
\text { coletivamente. }\end{array}$ \\
\hline $\begin{array}{l}\text { VIEIRA MG, et al. } \\
\text { (2016). }\end{array}$ & $\begin{array}{l}\text { Auto-mutilação: intensidade da } \\
\text { dor, fatores desencadeantes e } \\
\text { recompensadores. }\end{array}$ & Revista Dor. & $\begin{array}{l}\text { Identificar a intensidade da dor que } \\
\text { mais atende à necessidade de } \\
\text { automutilação. }\end{array}$ & $\begin{array}{l}\text { Em relação à intensidade da dor de acordo com a } \\
\text { escala numérica } 45 \% \text { não relataram dor, } 35 \% \text { dor } \\
\text { leve, } 15 \% \text { dor moderada e } 5 \% \text { dor intensa. Porém, } \\
\text { ao considerar a dor interpretada fora do momento } \\
\text { da crise, } 5 \% \text { não relataram dor, } 45 \% \text { dor moderada } \\
\text { e } 50 \% \text { dor intensa. }\end{array}$ \\
\hline
\end{tabular}

Fonte: Oliveira A, et al., 2021. 


\section{DISCUSSÃO}

A palavra adolescência tem origem latina e possui significado "para crescer". De acordo com a Organização Mundial da Saúde (OMS) este período de desenvolvimento ocorre entre os 10 e 19 anos (OLIVEIRA TA, 2016). Rodrigues PP (2018) exibiu em seu estudo o conceito do período de adolescência criado pelo Estatuto da Criança e do Adolescente (ECA), de acordo com Art. $2^{\circ}$ das disposições preliminares do Estatuto, define a adolescência como a faixa etária entre 12 a 18 anos de idade.

A adolescência consiste em um período de amadurecimento, no qual o indivíduo sofre mudanças biológicas, psicológicas e sociais que podem influenciar em comportamentos violentos tanto para si ou para pessoas próximas. Isso pode ser marcado pela transição da identidade infantil para um indivíduo com uma imagem corporal diferente, estranha, passando a ter um corpo semelhante ao adulto. Aos poucos, eles vão atribuindo a esse corpo um território privilegiado de comunicação para expressar aqueles sentimentos não ditos, representados por seus conflitos mais internos que muitas vezes os sufocam (TENÓRIO MMC, et al., 2019; ALMEIDA RS, et al., 2018).

De acordo com Novais RM (2018), diante dessa fase de transição conflituosa o adolescente se depara com um sentimento de angústia e com dificuldades de percorrer essa travessia ocorrendo a interdição do seu desenvolvimento. Oliveira TA (2016) em seu estudo mostrou que o jovem começa a apresentar uma menor proximidade com os pais e passa a se relacionar com seus pares. Sendo assim, um bom relacionamento com seus pares reflete em um ajustamento psicológico positivo.

Ao dissertar sobre as situações de automutilação em seu artigo: Do corpo objeto ao corpo vivido: aproximações entre automutilação e fenomenologia, Rodrigues PP (2018) apresentou a adolescência como um momento de desunião entre a família, em decorrência do adolescente encontrar-se em uma fase de questionamentos e reflexões que fazem com que não consigam seguirem regras, aumentando conflitos e sentimentos de não aceitação e compreensão de seus pais.

Reis CES (2018) informou em sua pesquisa que aqueles que buscam controlar as suas emoções possuem a tendência de desenvolverem comportamentos não adaptativos e antissociais, já aqueles que permitem experimentar e viver suas emoções são propensos a apresentarem uma maior adaptação interpessoal. Portanto, a variabilidade emocional e o ajustamento psicológico estão relacionados, sugerindo que adolescentes incapazes de lidar com suas emoções possam desenvolver alguma psicopatologia devido a sintomas depressivos diante da não adaptação social.

Em relação ao corpo e às marcas corporais, Tenório MMC, et al. (2019) enfatizaram que são resultados do complexo social em que o adolescente está inserido. Dessa maneira, a sua relação com o mundo ocorre através da pele, sendo necessário, às vezes, a reorganização de sua superfície para nela se sentir melhor. Com a necessidade de redefinir aquilo que o identifica, o indivíduo pode sentir-se desamparado pelas incertezas e os sentimentos que geralmente não são expressos, em alguns adolescentes são denunciados por uma produção de linguagem corporal, ao invés de uma linguagem oral.

Ao se comparar com Novais RM (2018), percebeu-se uma concordância, pois, assim como Tenório MMC, et al. (2019) afirmaram que o corpo é o primeiro meio de contato com o mundo, dessa forma, com a presença de sentimentos, de angústias provoca uma exteriorização somática através de cortes, queimaduras ou perfurações em seu corpo.

Em contrapartida, Moraes WCD (2018) diverge dos demais autores, ao afirmar que apesar do jovem precisar viver socialmente e que o grupo seja necessário, um grupo de jovens deprimidos, seja presencialmente ou utilizando a internet pode ser maléfico e ser uma experiência tóxica. Segundo ele, o compartilhamento de experiências dos adolescentes sobre suas angústias e dores exerce forte influência, logo, se um indivíduo se corta, os outros farão o mesmo para sentir-se integrado naquele grupo.

Similarmente, Tang J, et al. (2020) observaram uma associação da autolesão não suicida com a internet, porém é difícil ter certeza de que o vício em redes sociais resultou na automutilação ou vice-versa. No entanto, foi percebido que aqueles adolescentes que são dependentes digitais e praticam a autolesão podem ter sofrimentos psíquicos maiores que os outros e usam tanto a internet como as lesões corporais para alívio da dor. 
Além disso, Moraes DX, et al. (2020) citaram que houve evidências de que a exposição das fotos de jovens que praticam autolesão não suicida nas redes sociais como Instagram, Facebook e WhatsApp, é um risco para influenciar os adolescentes a desenvolverem automutilação, pois conhecer outras pessoas que se autolesionam e disseminam declarações persuasivas acaba por estimular com que o indivíduo acredite que esse ato é benéfico.

Lima CSA, et al. (2021) observou que indivíduos que apresentam sentimento de vazio tende a se conformar com relacionamentos abusivos na tentativa de sentir-se acolhida. Essas relações de dependência influenciam na incapacidade de conter sua ansiedade diante das dificuldades, assim para conseguir algum alívio do sofrimento psíquico, surgem os comportamentos de destruição da pele, com o objetivo de distanciar o foco da dor psíquica para a dor física.

Segundo Novais RM (2018), os adolescentes que apresentou dificuldades quanto ao seu desenvolvimento emocional e social, assim como as características da sua personalidade e resiliência que estão sendo desenvolvidas, determinaram a tendência deste sujeito a desenvolver psicopatologias.

No estudo realizado por Tenório MMC, et al. (2019), no qual foram entrevistados cerca de 15 psicólogos, foi possível observar que $80 \%$ deles certificaram que a maioria dos casos de automutilação, atendidos nos últimos anos, esteve associado a algum quadro de doenças psíquicas. Já os outros $20 \%$ enfatizam que o ato de se lesar pode não está associado a uma psicopatologia, devendo destacar o meio em que o jovem está inserido para conhecer os fatores que justificam tais ações.

A automutilação é vista como um sintoma de alguns transtornos mentais. Dentre eles destaca-se o Transtorno de Personalidade Borderline, do qual a automutilação faz parte do quinto critério de diagnóstico para esse transtorno (TENÓRIO MMC, et al., 2019). De acordo com Lopes LS e Teixeira LC (2019) é comum os sintomas da prática autolesiva serem mascaradas por transtornos psiquiátricos como ansiedade, dislexia, depressão, transtorno borderline, quando na realidade são indivíduos buscando se expressar por meio da sua pele, principalmente entre o sexo feminino.

Foi demonstrado no estudo de Li W, et al. (2020) que diante do contexto da pandemia de COVID-19 os pacientes com doença mental grave foram atingidos, o qual revelou que em fevereiro de 2020, 323 pessoas com doenças mentais se infectaram com o vírus e enfrentaram dificuldades no tratamento por causa do isolamento social e como consequência começaram a ter comportamentos de hiperatividade, agitação e automutilação.

Rodrigues PP (2018) também afirmou que os transtornos psiquiátricos intensificam o comportamento autolesivo na tentativa de diminuição do sofrimento. Define automutilação como qualquer ato consciente de ataque ao próprio corpo, não havendo a intensão de suicídio, que geralmente se inicia entre os 13 e 14 anos de idade do adolescente.

Vieira MG, et al. (2016), em sua pesquisa sobre os fatores associados à automutilação realizada com 20 pacientes de idades entre 16 a 60 anos, perceberam que $55 \%$ dos pacientes que se automutilaram foram diagnosticados com depressão maior; $20 \%$ com ansiedade; $15 \%$ com raiva, medo ou frustações. Ademais, dentre os fatores que desencadearam a automutilação, o principal foi a tristeza relatada por $70 \%$ dos entrevistados.

As pessoas ao serem expostas a um distanciamento social, como foi na pandemia da COVID-19, estão sujeitas a desenvolverem sentimentos negativos e irritabilidade. Desse modo, o medo de se contaminar ou que alguém querido fique doente, além das diversas informações que relacionam a morte, são situações que podem anteceder quadros de Transtornos do Pânico, Transtorno Obsessivo Compulsivo e Transtorno de Estresse Pós-Traumático (LIMA SO, et al., 2020).

A divulgação excessiva de notícias nas redes sociais favorece o recebimento de informações negativas e falsas, o que promove uma desconfiança em acompanhar as informações verdadeiras que poderiam ajudar nesse período, e provocam angústia e ansiedade (VASCONCELOS SE, et al., 2020). Vasconcelos SE, et al. (2020) também citaram em seu estudo a relação dos prejuízos que agravam a saúde mental, referentes a momentos de epidemias, sendo fator de risco para o desenvolvimento de problemas como depressão e 
ansiedade, justificada por uma instabilidade financeira provocada pela situação. Além disso, Lima SO, et al. (2020) complementaram que em pacientes com transtornos psiquiátricos essa situação tende a ser pior, exacerbando-os, havendo uma intensificação do medo e de frustações com a instabilidade de respostas para o controle viral, no caso da COVID-19. Existem várias classificações para automutilação, segundo o Manual Diagnóstico e Estatístico de Transtornos Mentais (2014), define-se automutilação a partir dos seguintes critérios (Quadro 2).

Quadro 2 - Critérios para a Definição de Automutilação.

\begin{tabular}{|c|l|}
\hline Critério A & $\begin{array}{l}\text { O indivíduo se automutilou durante cinco ou mais dias, no último ano, provocando } \\
\text { sangramento, dor ou contusão, sem a intenção suicida confirmada pelo indivíduo ou } \\
\text { clareza de que o ato não resultará em sua morte. }\end{array}$ \\
\hline Critério B & $\begin{array}{l}\text { O indivíduo possui uma ou mais das expectativas seguintes com a autolesão } \\
\text { intencional, sendo comum a repetição dos atos devido ao alívio ser momentâneo: } \\
\text { 1. Obter alívio de um estado de sentimento ou de cognição negativos. } \\
\text { 2. Resolver uma dificuldade interpessoal. } \\
\text { 3. Induzir um estado de sentimento positivo. }\end{array}$ \\
\hline Critério C & $\begin{array}{l}\text { O comportamento está associado a um ou mais dos seguintes tópicos: } \\
\text { 1.A autolesão intencional é precedida de dificuldades interpessoais ou estados de } \\
\text { negatividades como depressão, ansiedade, raiva, tensão, angústia, } \\
\text { autodesvalorização. } \\
\text { 2. O ato é precedido por um período de preocupação, apresentando falta de controle } \\
\text { sobre tal sentimento. } \\
\text { 3. Pensamentos constantes sobre a automutilação, mesmo sem a prática do ato. }\end{array}$ \\
\hline Critério D & $\begin{array}{l}\text { O comportamento não se limita a arrancar cascas de feridas ou roer unhas e não são } \\
\text { aceitos socialmente, como rituais religiosos, cultos, tatuagens e piencing corporal). }\end{array}$ \\
\hline Critério E & $\begin{array}{l}\text { Possui sofrimento considerável clinicamente decorrente das complicações do seu } \\
\text { comportamento ou prejuízos no funcionamento em áreas importantes de sua vida } \\
\text { como interpessoal, acadêmica e profissional. }\end{array}$ \\
\hline Critério F & $\begin{array}{l}\text { O ato não está associado exclusivamente a episódios psicóticos, delírio, intoxicação } \\
\text { por substâncias ou abstinência de substância; ausência de estereotipias repetitivas } \\
\text { em indivíduos com transtorno do neurodesenvolvimento; o comportamento não é } \\
\text { melhor explicado por outra patologia. }\end{array}$ \\
\hline
\end{tabular}

Fonte: Oliveira A, et al., 2021; dados extraídos do Diagnostic and Statistical Manual of Mental Disorders V (DSM-V), 2014.

Em consonância a isso, além da classificação da automutilação já citada, Moreira DX, et al. (2020) demonstrou que a automutilação pode ser dividida em dois grupos distintos, sendo o Deliberate self harm que engloba todas as maneiras de automutilação sem distinguir a intenção suicida ou não; e o Non Suicidal Self Injury que se refere somente aos danos a pele como arranhões, cortes e queimaduras com ausência da intenção de morrer

Durante séculos o homem busca atribuir significado ao ato de mutilar o próprio corpo. Segundo Moraes WCD (2018), na idade média o ato de se mutilar significava um distanciamento de Deus, além de denominar como histéricas as mulheres que se furavam com agulhas. Já no final do século XIX, os autores Freitas EQ e Souza R (2017) descreveram a lesão autoprovocada já relacionada com elementos culturais, através de tatuagem, piercings e mutilações, que eram representadas como símbolos de diferentes grupos sociais como os marinheiros, circenses, prostitutas e homossexuais.

Izadi-Mazidi M, et al. (2019), em um estudo realizado entre estudantes iranianos do ensino médio publicado pela revista Iranian Journal of Psychiatry, buscaram analisar a automutilação não suicida a partir do Modelo de Quatro Funções (Quadro 3), no qual observou-se que a regulação da emoção foi o processo que causa automutilação não suicida mais endossado do que a regulação do ambiente social. 
Quadro 3 - Modelo de Quatro Funções.

\begin{tabular}{|l|l|}
\hline 1- Reforço Negativo Automático & $\begin{array}{l}\text { Automutilação não suicida seguido por uma diminuição ou } \\
\text { eliminação de emoções ou cognições aversivas. }\end{array}$ \\
\hline 2- Reforço Positivo Automático & $\begin{array}{l}\text { Automutilação não suicida seguido por um aumento ou geração de } \\
\text { sentimentos positivos ou estados cognitivos. }\end{array}$ \\
\hline 3- Reforço Social Negativo & $\begin{array}{l}\text { Automutilação não suicida seguido por uma diminuição ou } \\
\text { eliminação de eventos sociais aversivos. }\end{array}$ \\
\hline 4- Reforço Social Positivo & $\begin{array}{l}\text { Automutilação não suicida seguido por um aumento ou geração de } \\
\text { eventos sociais desejados }\end{array}$ \\
\hline
\end{tabular}

Fonte: Oliveira A, et al., 2021; dados extraídos dos autores Izadi-Mazidi M, et al., 2019.

De forma similar, Santos AA, et al. (2019) realizaram um estudo de caso onde analisaram 10 adolescentes da Educação Básica, constatando as principais causas da automutilação destacando-se problemas familiares como o luto, discussões, divórcios e doenças. Além disso, relacionamentos interpessoais caracterizados por relacionamentos amorosos, decepção de amizades e influência de amigos. Desse modo, notou-se que entre as causas de automutilação não suicida, a falta de controle sobre o próprio estado emocional diante de situações adversas contribuiu para o quadro do indivíduo.

Em "Caneta é a lâmina, minha pele o papel": fatores de risco da automutilação em adolescentes, Morais DX, et al. (2020) observaram que as condições aborrecedoras que resultem em perturbações físicas ou psicológicas como um assassinato de uma pessoa querida, revelam sentimentos de medo, tristeza, abandono e decepção e podem estimular o início da automutilação.

Os principais fatores de risco para a prática da lesão autoprovocada, de acordo com a pesquisa de Moreira ES, et al. (2020) realizada em sete países da Europa são: ser mulher; ter sofrido ou sofrer abuso sexual ou agressão física; vítimas de bullying; consumo excessivo de álcool e drogas; términos de relacionamentos. Também endossam a lista: relacionamentos maternos instáveis; desamparo familiar; relação com pessoas que se automutilam; insônia; impulsividade; baixa autoestima; nível socioeconômico baixo; baixa escolaridade; dificuldade de expressar sentimentos ou enfrentar problemas; não ter religião e a autocrítica.

Almeida RS, et al. (2018) listaram os principais fatores de risco que colaboram para desenvolver o comportamento de lesar o próprio corpo, que englobam características pessoais, como a falta de mecanismos de adaptação, pessimismo, insegurança, distorção da imagem corporal, instabilidade emocional, impulsividade e auto desvalorização. Quanto aos transtornos psiquiátricos destacam a ansiedade, depressão e transtornos de personalidades. Além disso, constatou-se problemas relacionados à infância, por exemplo, abuso sexual, físico e emocional, negligência e estresse emocional precoce. Ademais, pontuou os fatores de risco sociais: bullying e informação sobre automutilação, principalmente pelas redes sociais onde compartilham suas experiências havendo um contágio social. Por último, em relação à família tem-se dependência de álcool, separação precoce dos pais e relação familiar disfuncional.

Além disso, Tang J, et al. (2020) pontuam que o uso inadequado da internet está associado ao ato de automutilar-se. Em um estudo transversal entre adolescentes realizado na China no período de agosto de 2018 a março de 2019, observou-se que os adolescentes envolvidos com a automutilação não suicida e o vício em internet podem ter mais problemas psicológicos e usar esses comportamentos para obter o que consideram um alívio do sofrimento.

Santos AA, et al. (2019) acrescentam, de acordo com a Sociedade Internacional de Estudo da Violência Autodirigida, que há também fatores protetores, tais como: as boas relações familiares; bom suporte social; boas competências sociais; estilo de vida saudável; identificação efetiva com valores culturais e boas relações interpessoais. Sendo assim, ao comparar os estudos, observa-se que quando os fatores de riscos sobrepõem os fatores protetores, os adolescentes tornam-se mais propensos a desenvolver comportamentos autolesivos.

Rodrigues PP (2018) e Almeida RS, et al. (2018) esclareceram a associação entre automutilação e suicídio e a importância da sua diferenciação. Eles afirmaram que indivíduos que se lesionam apresentaram atos repetitivos, pois apesar de causarem dor este ato diminui o sentimento de angústia momentaneamente, não 
possuindo intenção consciente de suicídio, porém apresenta risco. Na maioria dos casos a própria autolesão provocada é vista como uma punição, sem a necessidade de provocar o suicídio mesmo que isso possa ocorrer de forma acidental.

Em concordância, Novais RM (2018), afirmou que a automutilação voluntária possui finalidade de realizar cortes no próprio corpo sem intenção consciente de suicídio, no entanto, o mal-estar instalado no interior do sujeito que instiga a autolesão, também pode futuramente estimular pensamentos suicidas.

Segundo Santos NM, et al. (2021), a automutilação é uma prática que deve ser um alerta aos familiares e a equipe de saúde, pois pode ser incluída como fator de risco, ou um sinal de que esse indivíduo poderá suicidar-se. Por isso, Pereira RG, et al. (2019) demonstrou a necessidade da determinação de medidas para a prevenção de um suicídio, como a participação desse jovem em terapias individuais ou em grupo, uso de medicamentos e acompanhamento com psiquiatra, incluir esse indivíduo na sociedade com realização de tarefas em grupo.

Além disso, existem fatores protetores ao suicídio como o desenvolvimento de capacidade de se interagir socialmente, de procurar por apoio social ou médico, valorizar a si mesmo, permitir-se a praticar novas experiências e desenvolver novas relações (SANTOS NM, et al. 2021).

Diante dessa relação e da importância do número crescente de casos, o Presidente da República criou a Lei № 13.819, de 26 de abril de 2019, que institui a Política Nacional de Prevenção de Automutilação e de Suicídio. A política tem como objetivo a promoção de saúde mental, a prevenção da violência autoprovocada, o controle dos fatores determinantes e condicionantes da saúde mental e garantir o acesso psicossocial. Também há o propósito de informar e sensibilizar a sociedade que se trata de um problema de saúde pública que pode ser prevenido, além disso, ser necessário a notificação dos casos, dentre outros objetivos (BRASIL, 2019a).

\section{CONSIDERAÇÕES FINAIS}

Percebeu-se a importância do conhecimento das causas que influenciam os adolescentes a se automutilarem, que contribuem de forma negativa para o seu desenvolvimento biológico, mental e social, considerando a adolescência uma fase de maior vulnerabilidade por estarem em constantes mudanças e adaptações. Além disso, é importante a quebra do tabu sobre automutilação entre jovens, informando profissionais da educação para combater a negligência em relação a este tema. Dessa forma, espera-se que com o conhecimento das causas, principalmente entre pais, profissionais da saúde e educação, que levam o adolescente a praticar lesão autoprovocada, seja possível prevenir a ocorrência ade novos casos através das informações divulgadas, reduzindo assim esse problema de saúde pública.

\section{REFERÊNCIAS}

1. ALMEIDA RS, et al. A prática da automutilação na adolescência: o olhar da psicologia escolar/ educacional. Caderno de Graduação - Ciências Humanas e Sociais. 2018; 4(3): 147-160.

2. BRASIL. Lei no 13.819, de 26 de abril de 2019. Institui a Política Nacional de Prevenção da Automutilação e do Suicídio, a ser implementada pela União, em cooperação com os Estados, o Distrito Federal e os Municípios; e altera a Lei $\mathrm{n}^{\circ}$ 9.656, de 3 de junho de 1998. Brasília: Diário Oficial da União, 2019a; 1:1. Disponível em: https://www.in.gov.br/web/dou/-/lei-n\%C2\%BA-13.819-de-26-de-abril-de-2019-85673796. Acessado em: 4 abril de 2021.

3. BRASIL. Boletim Epidemiológico 001/2019. Panorama da violência interpessoal/autoprovocada a partir da análise sobre o preenchimento da ficha de notificação. Rio de Janeiro: Secretaria de Vigilância em Saúde. Ministério da Saúde, 2020b; 26p. Disponível em: http://www.riocomsaude.rj.gov.br/Publico/MostrarArquivo.aspx?C=wdMTu5zzZ\%2BE\%3D. Acesso em: 5 de abril de 2021.

4. CIDADE NOP, ZORNIG SMAJ. Automutilações na adolescência: reflexões sobre o corpo e o tempo. Estilos da Clínica, $2021 ; 26(1): 129-144$.

5. DIAGNOSTIC AND STATISTICAL MANUAL OF MENTAL DISORDERS V (DSM-V). Manual de Diagnóstico e Estatística de Transtornos Mentais (DSM-5). 5.ed. Porto Alegre: Artmed, 2014; 1: 803-804.

6. FREITAS EQ, SOUZA R. Automutilação na adolescência: prevenção e intervenção em psicologia escolar. Revista Ciência (In)Cena, 2017; 1(5): 158-174. 
7. IZADI-MAZIDI M, et al. Assessing the functions of non-suicidal self-injury: factor analysis of functional assessment of self-mutilation among adolescents. Iranian journal of psychiatry, 2019; 14(3): 184.

8. LIMA CSA, et al. Transtorno de Personalidade Borderline e sua relação com os comportamentos autodestrutivos e suicídio. Revista Eletrônica Acervo Saúde, 2021; 13(4): e7052-e7052.

9. LIMA SO, et al. Impactos no comportamento e na saúde mental de grupos vulneráveis em época de enfrentamento da infecção COVID-19: revisão narrativa. Revista Eletrônica Acervo Saúde, 2020; Esp(46): e4006-e4006.

10. LI W, et al. Progression of mental health services during the COVID-19 outbreak in China. International journal of biological sciences, 2020; 16(10): 1732.

11. LOPES LS, TEIXEIRA LC. Automutilações na adolescência e suas narrativas em contexto escolar. Estilos da Clínica - Revista USP. 2019; 24(2): 291-303.

12. MORAES DX, et al. "Caneta é a lâmina, minha pele o papel": fatores de risco da automutilação em adolescentes. Revista Brasileira de Enfermagem, 2020; 73: e20200578.

13. MORAES WCD. Angústias da automutilação. Trabalho de Conclusão de Curso (Bacharel em Psicologia) Universidade Faculdades de Atibaial, Atibaia- SP, 2018; 27p.

14. MOREIRA ES, et al. Self-mutilation among adolescents: an integrative review of the literature. Ciência \& Saúde Coletiva, 2020; 25(10): 3945-3954.

15. NOVAIS RM. Automutilação: O Encontro entre o real do Sofrimento e o sofrimento real. POLÊMICA, 2018; 18(1): 050067.

16. OLIVEIRA TA. Automutilação do corpo entre adolescentes: um sintoma social ou alerta de transtorno mental?. Trabalho de Conclusão de Curso (Especialista em Saúde Mental) - Escola Bahiana de Medicina e Saúde Pública, Salvador, 2016, 20p.

17. PEREIRA RG, et al. Análise do perfil do paciente suicida: revisão integrativa. Revista Eletrônica Acervo Saúde, 2019; Sup(25): e607-e607.

18. REIS CES. Do corpo objeto ao corpo vivido: aproximações entre automutilação e fenomenologia. IGT na Rede, 2018; 15(29): 131-146.

19. RODRIGUES PP. Gritos silenciosos: quando as impossibilidades de simbolização de conflitos retornam ao corpoautomutilação na adolescência. Monografia (título de Especialista em Saúde do Adolescente) - Departamento de Pediatria da Faculdade de Medicina da Universidade Federal de Minas Gerais, Belo Horizonte- MG, 2018, 31p.

20. SANTOS AA, et al. Automutilação na adolescência: compreendendo suas causas e consequências (Self-mutilation in adolescence: understanding its causes and consequences). Temas em Saúde, 2019; 18(3): 116-142.

21. SANTOS NM, et al. Prevalência de ideação suicida em acadêmicos da área de saúde. Revista Eletrônica Acervo Saúde, 2021; 13(4): e6447-e6447.

22. TANG J, et al. Association of internet addiction with nonsuicidal self-injury among adolescents in China. JAMA network open, 2020; 3(6): e206863-e206863.

23. TENÓRIO MMC, et al. A Percepção De Psicólogos Acerca Da Automutilação Em Jovens. Revista Científico, 2019; 19(40): 67-86.

24. VASCONCELOS SE, et al. Impactos de uma pandemia na saúde mental: analisando o efeito causado pelo COVID19. Revista Eletrônica Acervo Saúde, 2020; 12(12): e5168-e5168.

25. VIEIRA MG, et al. Self-mutilation: pain intensity, triggering and rewarding factors. Revista Dor, 2016; 17(4): $257-260$. 